\title{
Stator Faut Detection for the Input Output Control of the Permanent Magnet Synchronous Motor
}

\author{
Maanani Y*, Menacer A, Harzelli I and Zouzou S \\ Department of Engineering, Biskra University, Algeria \\ Submission: March 08, 2018; Published: April 20, 2018 \\ "Corresponding author: Maanani, Department of Engineering, Biskra University, Biskra/Algeria, yacine.maanani@gmail.com
}

Abstract

In this paper, a simple dynamic model for a PMSM with inter-turn winding fault in closed loop. The control of the PMSM is assured by the input-output control. The objective of this paper is the detection and location of the stator winding fault severity of PMSM. To achieve this objective, a mathematical model that can describe both healthy and fault conditions is developed. Simulation results match the observations of this type of fault in the literature.

Keywords: Permanent magnets synchronous machine; Inter turn; Fault detection; Input-output control

\section{Introduction}

Permanent magnet synchronous motor PMSM has received widespread acceptance, mainly in high performance of its applications for renewable energy generator or industrial servo applications of accurate speed and position control. This is due to some of its excellent features such as super power density, high torque to current ratio, fast response and low noise [1].

Nonlinear control has the advantage of separately current and torque. With this control technology, engine model is broken down into two independent systems mono variable linear. Each subsystem is an independent control loop of a given variable (speed, torque, current etc.). The dynamics of the linearized system is chosen through optimal taxation of poles [2].

The PMSM are generally robust, their frequent exposure to severe circumstances inclines them to certain fault conditions after continuous operation. The possible fault modes in PMSM include electrical and mechanical sources [3]. Statistics show that the most electric motor failures are due to electrical faults, among which the stator winding faults constitute the largest portion [4]. Stator winding faults usually are caused by insulation breakdown between coils in the same phase or different phases. While the winding "short" usually emerges locally as an incipient fault, it can propagate rapidly, culminating in the failure of the entire phase. This is due to the increased ohmic heating associated with the high current in the shorted portion of the winding, which eventually leads to a significant rapid temperature increase and causes faster deterioration of the insulation system [5]. Therefore, an effective diagnostic system for these faults in motors is necessary to improve the reliability of such motors.
The mathematical analysis and computer simulation are more versatile and cost effective methods for gaining insight into the system dynamics under fault operating conditions. Recently, several studies on faulty electric machine dynamic modeling have been published. These studies use various methods for different purposes [6]. Fault modeling is becoming an important part of the fault diagnosis design process. In this paper, a new model for the stator winding fault of PMSM is proposed based upon the coupled magnetic circuit principle. The model is compatible with both healthy operation and operation under asymmetrical stator winding fault (turn-to-turn short) conditions. Simulation results of the fault model match the observations of this kind of fault in the literature. In the developed fault model, two parameters are used, one to represent fault location and one for fault severity. If these two parameters can be identified and are beyond a certain range, then the occurrence of a stator winding fault can be concluded.

In general, monitoring and diagnosis require the detection and analysis of signals containing specific information (symptoms or signatures) that characterizes the degradation of the machine [7]. FFT analysis of one of the stator currents has become a standard procedure for diagnosing the state of a permanent magnet synchronous motor. However [8], Even though the method gives successful results for stationary signals, it is not successful for non-stationary signals due to the inadequacy of the FFT method. Since PMSMs are operated according to the determined acceleration and deceleration reference speeds, both the amplitude and the frequency of the current drawn in these regions are dynamic [9]. 


\section{Dynamic Model of the PMSM with Inter Turn Fault}

An inter-turn fault denotes an insulation failure between two windings in the same phase of the stator. The insulation failure is modelled by a resistance, where its value depends on the fault severity. The stator winding of a PMSM machine with inter-turn fault is represented in Figure 1, where the fault is occurred in the phase as and $\left(r_{f}\right)$ represents the fault insulation resistance. The sub-windings $\left(a_{s 1}\right)$ and $\left(a_{s 2}\right)$ represent the healthy and faulty part of the phase winding a respectively.

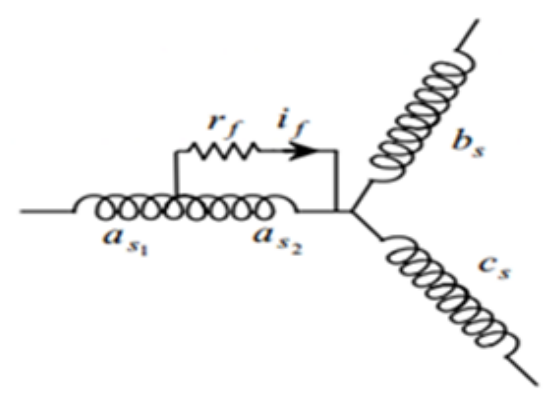

Figure 1: Three phase winding with inter-turn fault in the phases

When the fault resistance $\left(r_{f}\right)$ decreases toward zero, the insulation fault evaluates toward an inter-turn full short-circuit. The evolution of fault insulation resistance between $r_{f}=\infty$ and $r_{f}=0$ is very fast in most insulation materials. It is important to predict the inter-turn fault when it is not high developed and the fault resistance is still not very near to zero. Therefore, in our fault model, the fault insulation resistance is included and the machine behavior with various fault resistances is studied [10].

\section{Fault model in ABC coordinates}

Setting up the mesh equations for the circuit in Figure 1 will express the voltage equations as:

$$
\mathrm{V}_{\mathrm{s}}=\left[\mathrm{R}_{s}\right] \cdot\left[\mathrm{I}_{s}\right]+\left[\mathrm{L}_{s s}\right] \frac{\mathrm{d}}{\mathrm{dt}}\left[\mathrm{I}_{s}\right]+\left[\mathrm{E}_{s}\right]
$$

Where $\left[\mathrm{V}_{\mathrm{s}}\right],\left[\mathrm{I}_{s}\right]$ and $\left[\mathrm{E}_{s}\right]$ are the stator voltage, current and back-EMF vectors:

$$
\mathrm{V}_{\mathrm{s}}=\left[\begin{array}{lll}
\mathrm{v}_{a s} & \mathrm{v}_{b s} & \mathrm{v}_{c s}
\end{array}\right]^{\mathrm{T}}, \mathrm{I}_{\mathrm{s}}=\left[\begin{array}{lll}
\mathrm{I}_{a s} & \mathrm{I}_{b s} & \mathrm{I}_{c s}
\end{array}\right]^{\mathrm{T}}, \mathrm{E}_{\mathrm{s}}=\left[\begin{array}{lll}
e_{a s} & \mathrm{e}_{b s} & \mathrm{e}_{c s}
\end{array}\right]^{\mathrm{T}}
$$

Rs: is the phase resistance and [ $L_{s s}$ ] is the inductance matrix of the healthy PMSM respectively:

$$
\left[\mathrm{R}_{\mathrm{s}}\right]=\left[\begin{array}{ccc}
\mathrm{R}_{s} & 0 & 0 \\
0 & \mathrm{R}_{s} & 0 \\
0 & 0 & \mathrm{R}_{s}
\end{array}\right], \quad\left[\mathrm{L}_{\mathrm{ss}}\right]=\left[\begin{array}{ccc}
\mathrm{L}_{s} & \mathrm{M} & \mathrm{M} \\
\mathrm{M} & \mathrm{L}_{s} & \mathrm{M} \\
\mathrm{M} & \mathrm{M} & \mathrm{L}_{s}
\end{array}\right]
$$

Where the inductance $L_{s}$ is the phase self inductance and M is the mutual inductance between phase windings of the healthy PMSM.

$R a 2$ and $L a 2$ represent the resistance and inductance of the faulty sub coil $\left(a_{s 2}\right)$. The parameters Ma1a2, Ma2b and Ma2 represent respectively the mutual inductances between the sub- coil $a_{s 2}$ and the coils $a_{s 1}, b s$ and $c s$. The fault current through the insulation fault resistance $r_{f}$ is also called $i_{f}$. For the machine having one slot per pole and per phase, $M a 2 b$ can be considered equal to $\mathrm{Ma} 2 \mathrm{c}$.

The voltage equation of the faulty loop $\left(a_{s 2}\right)$ is:

$$
\begin{aligned}
& 0=-\mathrm{R}_{a 2} \mathrm{I}_{a s}-\left(\mathrm{L}_{a 2}+\mathrm{M}_{a 1 a 2}\right) \frac{\mathrm{dI}_{a s}}{\mathrm{dt}}-\mathrm{M}_{a 2 b} \frac{\mathrm{dI}_{b s}}{\mathrm{dt}}-\mathrm{M}_{a 2 c} \frac{\mathrm{dI}_{c s}}{\mathrm{dt}}-\mathrm{e}_{a 2}+ \\
& \left(\mathrm{R}_{a 2}+\mathrm{r}_{f}\right) \mathrm{I}_{f}+\mathrm{L}_{a 2} \frac{\mathrm{dI}_{f}}{\mathrm{dt}}
\end{aligned}
$$

The equations of the voltages of the three phases are thus put in the form:

$$
\left\{\begin{array}{l}
\mathrm{V}_{a s}=\left(\mathrm{R}_{a 1}+\mathrm{R}_{a 1}\right) \mathrm{I}_{a s}+\left(\mathrm{L}_{a 1}+\mathrm{L}_{a 2}+2 \mathrm{M}_{a 1 a 2}\right) \frac{\mathrm{d}}{\mathrm{dt}} \mathrm{I}_{a s}+\left(\mathrm{M}_{a 1 b}+\mathrm{M}_{a 2 b}\right) \frac{\mathrm{d}}{\mathrm{dt}} \mathrm{I}_{b s}+ \\
\left(\mathrm{M}_{a 1 c}+\mathrm{M}_{a 2 c}\right) \frac{\mathrm{d}}{\mathrm{dt}} \mathrm{I}_{c s}+\left(\mathrm{e}_{a 1}+\mathrm{e}_{a 2}\right)-\mathrm{R}_{a 2} \mathrm{I}_{f}-\left(\mathrm{L}_{a 2}+\mathrm{M}_{a 1 a 2}\right) \frac{\mathrm{d}}{\mathrm{dt}} \mathrm{I}_{f} \\
\mathrm{~V}_{b s}=\mathrm{R}_{s} \mathrm{I}_{b s}+\mathrm{L} \frac{\mathrm{d}}{\mathrm{dt}} \mathrm{I}_{b s}+\left(\mathrm{M}_{a 1 b}+\mathrm{M}_{a 2 b}\right) \frac{\mathrm{d}}{\mathrm{dt}} \mathrm{I}_{a s}+\mathrm{e}_{c s}+\mathrm{M} \frac{\mathrm{d}}{\mathrm{dt}} \mathrm{I}_{c s}-\mathrm{M}_{a 2 b} \frac{\mathrm{d}}{\mathrm{dt}} \mathrm{I}_{f} \\
\mathrm{~V}_{c s}=\mathrm{R}_{s} \mathrm{I}_{c s}+\mathrm{L} \frac{\mathrm{d}}{\mathrm{dt}} \mathrm{I}_{c s}+\left(\mathrm{M}_{a 1 c}+\mathrm{M}_{a 2 c}\right) \frac{\mathrm{d}}{\mathrm{dt}} \mathrm{I}_{a s}+\mathrm{e}_{c s}+\mathrm{M} \frac{\mathrm{d}}{\mathrm{dt}} \mathrm{I}_{b s}-\mathrm{M}_{a 2 c} \frac{\mathrm{d}}{\mathrm{dt}} \mathrm{I}_{f}
\end{array}\right.
$$

The following relations are normally allowed:

$$
\begin{aligned}
& \mathrm{R}_{\mathrm{s}}=\mathrm{R}_{\mathrm{a}}=\mathrm{R}_{\mathrm{a} 1}+\mathrm{R}_{\mathrm{a} 2} \\
& \mathrm{~L}=\mathrm{L}_{\mathrm{a} 1}+\mathrm{L}_{\mathrm{a} 2}+2 \mathrm{M}_{\mathrm{a} 1 \mathrm{a} 2} \\
& \mathrm{M}=\mathrm{M}_{\mathrm{a} 1 \mathrm{~b}}+\mathrm{M}_{\mathrm{a} 2 \mathrm{~b}} \\
& \mathrm{M}=\mathrm{M}_{\mathrm{a} 1 \mathrm{c}}+\mathrm{M}_{\mathrm{a} 2 \mathrm{c}} \\
& \mathrm{e}_{\mathrm{a}}=\mathrm{e}_{\mathrm{a} 1}+\mathrm{e}_{\mathrm{a} 2}=\mathrm{e}_{\mathrm{a} 1}+\mathrm{e}_{\mathrm{f}}
\end{aligned}
$$

By replacing the above relations (4) in the electrical equations (3), we obtain the following matrix writing:

$$
\left.\begin{array}{c}
\mathrm{V}_{\mathrm{as}} \\
\mathrm{V}_{\mathrm{bs}} \\
\mathrm{V}_{\mathrm{cs}}
\end{array}\right]=\mathrm{R}_{s}\left[\begin{array}{l}
\mathrm{I}_{\mathrm{as}} \\
\mathrm{I}_{\mathrm{bs}} \\
\mathrm{I}_{\mathrm{cs}}
\end{array}\right]+\left[\begin{array}{ccc}
\mathrm{L}_{s} & 0 & 0 \\
0 & \mathrm{~L}_{s} & 0 \\
0 & 0 & \mathrm{~L}_{s}
\end{array}\right] \frac{\mathrm{d}}{\mathrm{dt}}\left[\begin{array}{l}
\mathrm{I}_{\mathrm{as}} \\
\mathrm{I}_{\mathrm{bs}} \\
\mathrm{I}_{\mathrm{cs}}
\end{array}\right]+\left[\begin{array}{l}
\mathrm{R}_{\mathrm{a} 2} \\
0 \\
0
\end{array}\right] \mathrm{I}_{f}-\left[\begin{array}{l}
\mathrm{L}_{\mathrm{a} 2}+\mathrm{M}_{\mathrm{ala} 2} \\
\mathrm{M}_{\mathrm{a} 2 \mathrm{~b}} \\
\mathrm{M}_{\mathrm{a} 2 \mathrm{c}}
\end{array}\right] \frac{\mathrm{dI}}{\mathrm{dt}}
$$

\section{Fault model in $A B$ coordinates}

For the star connected winding, the zero sequence component of the stator current is zero. Thus, the stator stationary reference frame transformation is applied:

$$
\left[\begin{array}{l}
x_{\alpha} \\
x_{\beta}
\end{array}\right]=\sqrt{\frac{2}{3}}\left[\begin{array}{ccc}
1 & -\frac{1}{2} & -\frac{1}{2} \\
0 & \frac{\sqrt{3}}{2} & -\frac{\sqrt{3}}{2}
\end{array}\right]\left[\begin{array}{l}
x_{a} \\
x_{b} \\
x_{c}
\end{array}\right]
$$

By representing the machine stator vectors by their components in the $\alpha \beta$ coordination, the PMSM machine equations with inter-turn fault (1) are simplified as follows:

$$
\left[V_{\alpha \beta}\right]=\mathrm{R}_{S}\left[I_{\alpha \beta}\right]+\left[\mathrm{L}_{\alpha \beta}\right] \frac{\mathrm{d}}{\mathrm{dt}}\left[\mathrm{I}_{\alpha \beta}\right]+\left[\mathrm{e}_{\alpha \beta}\right]-\left[\mathrm{L}_{0}^{\prime}\right] \frac{\mathrm{d}}{\mathrm{dt}}\left[\mathrm{I}_{f}\right]-\left[\mathrm{R}_{0}^{\prime}\right] \mathrm{I}_{f}
$$

For the faulty loop $\left(a_{s 2}\right)$, the voltage equation $\mathrm{n}$ the $\alpha \beta$ coordination becomes:

$$
\begin{aligned}
& 0=-\sqrt{\frac{2}{3}} \mathrm{R}_{a 2} \mathrm{I}_{a s}-\sqrt{\frac{2}{3}}\left(\mathrm{~L}_{\mathrm{a} 2}+\mathrm{M}_{\mathrm{al} \mathrm{a} 2}-\frac{\mathrm{M}_{\mathrm{a} 2 \mathrm{~b}}+\mathrm{M}_{\mathrm{a} 2 \mathrm{c}}}{2}\right) \frac{\mathrm{dI}_{a s}}{\mathrm{dt}} \\
& -\frac{1}{\sqrt{2}}\left(\mathrm{M}_{\mathrm{a} 2 \mathrm{~b}}-\mathrm{M}_{\mathrm{a} 2 \mathrm{c}}\right) \frac{\mathrm{dI}_{b s}}{\mathrm{dt}}-\mathrm{M}_{a 2 c} \frac{\mathrm{dI}_{c s}}{\mathrm{dt}}-\mathrm{e}_{a 2}+\left(\mathrm{R}_{a 2}+\mathrm{r}_{f}\right) \mathrm{I}_{f}+\mathrm{L}_{a 2} \frac{\mathrm{dI}_{f}}{\mathrm{dt}}
\end{aligned}
$$


Finally, the machine equations with inter-turn fault (7) in $\alpha \beta$ reference frame are written as follows:

$$
\begin{gathered}
{\left[\begin{array}{l}
V_{\alpha} \\
V_{\beta}
\end{array}\right]=\mathrm{R}_{s}\left[\begin{array}{l}
V_{\alpha} \\
V_{\beta}
\end{array}\right]+\mathrm{L}_{s} \mathrm{~d} \frac{1}{\mathrm{dt}}\left[\begin{array}{l}
\mathrm{I}_{\alpha} \\
\mathrm{I}_{\beta}
\end{array}\right]+\left[\begin{array}{l}
e_{\alpha} \\
e_{\beta}
\end{array}\right]-\sqrt{\frac{2}{3}}\left[\begin{array}{l}
\mathrm{R}_{\mathrm{a} 2} \\
0
\end{array}\right] \mathrm{I}_{f}-\left[\begin{array}{l}
\sqrt{\frac{2}{3}}\left(\mathrm{~L}_{\mathrm{a} 2}+\mathrm{M}_{\mathrm{a} 1 \mathrm{a} 2}-\frac{\mathrm{M}_{\mathrm{a} 2 \mathrm{~b}}+\mathrm{M}_{\mathrm{a} 2 \mathrm{c}}}{2}\right) \\
\frac{1}{\sqrt{2}}\left(\mathrm{M}_{\mathrm{a} 2 \mathrm{~b}}-\mathrm{M}_{\mathrm{a} 2 \mathrm{c}}\right)
\end{array}\right] \frac{\mathrm{d}_{f}}{\mathrm{dt}}} \\
{\left[\begin{array}{l}
V_{\alpha} \\
V_{\beta} \\
0
\end{array}\right]=\left[\begin{array}{ccc}
\mathrm{R}_{s} & 0 & -\mathrm{R}_{a 2}^{\prime} \\
0 & \mathrm{R}_{s} & 0 \\
-\mathrm{R}_{a 2}^{\prime} & 0 & \mathrm{R}_{f}^{\prime}
\end{array}\right]\left[\begin{array}{l}
\mathrm{I}_{\alpha} \\
\mathrm{I}_{\beta} \\
\mathrm{I}_{f}
\end{array}\right]+\left[\begin{array}{ccc}
\mathrm{L}_{s} & 0 & \mathrm{M}_{f \mathrm{a}} \\
0 & \mathrm{~L}_{s} & \mathrm{M}_{f \beta} \\
\mathrm{M}_{f \mathrm{a}} & 0 & \mathrm{~L}_{a 2}
\end{array}\right] \frac{\mathrm{d}}{\mathrm{dt}}\left[\begin{array}{l}
\mathrm{I}_{\alpha} \\
\mathrm{I}_{\beta} \\
\mathrm{I}_{f}
\end{array}\right]+\left[\begin{array}{l}
e_{\alpha} \\
e_{\beta} \\
-e_{f}
\end{array}\right]}
\end{gathered}
$$

With:

$$
\begin{gathered}
\mathrm{R}_{a 2}^{\prime}=\sqrt{\frac{2}{3}} \mathrm{R}_{a 2}, \mathrm{R}_{f}=\mathrm{R}_{a 2}+r_{f}, e_{\alpha}=e_{f} \\
\mathrm{M}_{f \mathrm{a}}=-\sqrt{\frac{2}{3}}\left(\mathrm{~L}_{\mathrm{a} 2}+\mathrm{M}_{\mathrm{a} 1 \mathrm{a} 2}-\frac{\mathrm{M}_{\mathrm{a} 2 \mathrm{~b}}+\mathrm{M}_{\mathrm{a} 2 \mathrm{c}}}{2}\right) \\
\mathrm{M}_{f \beta}=\frac{1}{\sqrt{2}}\left(\mathrm{M}_{\mathrm{a} 2 \mathrm{~b}}-\mathrm{M}_{\mathrm{a} 2}\right.
\end{gathered}
$$

As the zero sequence component of the current is zero, the electromagnetic torque expression (2) is:

$$
\mathrm{T}_{\mathrm{e}}=\frac{e_{\alpha} \mathrm{I}_{\alpha}+e_{\beta} \mathrm{I}_{\beta}-e_{\alpha 2} \mathrm{I}_{f}}{\Omega}
$$

\section{State space form of fault model}

For digital simulation of the electrical machine with inter turn fault, it is more convenient to express the dynamic equations in the state space form. The (10) can be written as:

$$
\frac{\mathrm{d}}{\mathrm{dt}}\left[\begin{array}{c}
\mathrm{I}_{\alpha} \\
\mathrm{I}_{\beta} \\
\mathrm{I}_{f}
\end{array}\right]=\left[\begin{array}{ccc}
\mathrm{L}_{s} & 0 & \mathrm{M}_{f \mathrm{a}} \\
0 & \mathrm{~L}_{s} & \mathrm{M}_{f \beta} \\
\mathrm{M}_{f \mathrm{a}} & 0 & \mathrm{~L}_{a 2}
\end{array}\right]^{-1}\left(\left[\begin{array}{ccc}
\mathrm{R}_{s} & 0 & -\mathrm{R}_{a 2}^{\prime} \\
0 & \mathrm{R}_{s} & 0 \\
-\mathrm{R}_{a 2}^{\prime} & 0 & \mathrm{R}_{f}^{\prime}
\end{array}\right]\left[\begin{array}{l}
\mathrm{I}_{\alpha} \\
\mathrm{I}_{\beta} \\
\mathrm{I}_{f}
\end{array}\right]\right)+\left[\begin{array}{l}
v_{\alpha}-e_{\alpha} \\
v_{\beta}-e_{\beta} \\
e_{f}
\end{array}\right]
$$

The state vector $(\mathrm{x})$ and input vector $(\mathrm{u})$ are supposed as:

$$
\mathrm{x}=\left[\begin{array}{l}
\mathrm{I}_{\alpha} \\
\mathrm{I}_{\beta} \\
\mathrm{I}_{f}
\end{array}\right], \quad u=\left[\begin{array}{l}
v_{\alpha}-e_{\alpha} \\
v_{\beta}-e_{\beta} \\
e_{f}
\end{array}\right]
$$

Thus, the machine fault model (10) in the state space form can be expressed as:

$$
\stackrel{\bullet}{x}=A x+B u
$$

With:

$$
\mathrm{A}=-\left[\begin{array}{ccc}
\mathrm{L}_{s} & 0 & \mathrm{M}_{f \mathrm{a}} \\
0 & \mathrm{~L}_{s} & \mathrm{M}_{f \beta} \\
\mathrm{M}_{f \mathrm{a}} & 0 & \mathrm{~L}_{a 2}
\end{array}\right]^{-1}\left[\begin{array}{ccc}
\mathrm{R}_{s} & 0 & -\mathrm{R}_{a 2}^{\prime} \\
0 & \mathrm{R}_{s} & 0 \\
-\mathrm{R}_{a 2}^{\prime} & 0 & \mathrm{R}_{f}^{\prime}
\end{array}\right]
$$

The state space equation (14) can be used for digital simulation. The simulation block diagram for PMSM with interturn fault is shown in Figure 2.

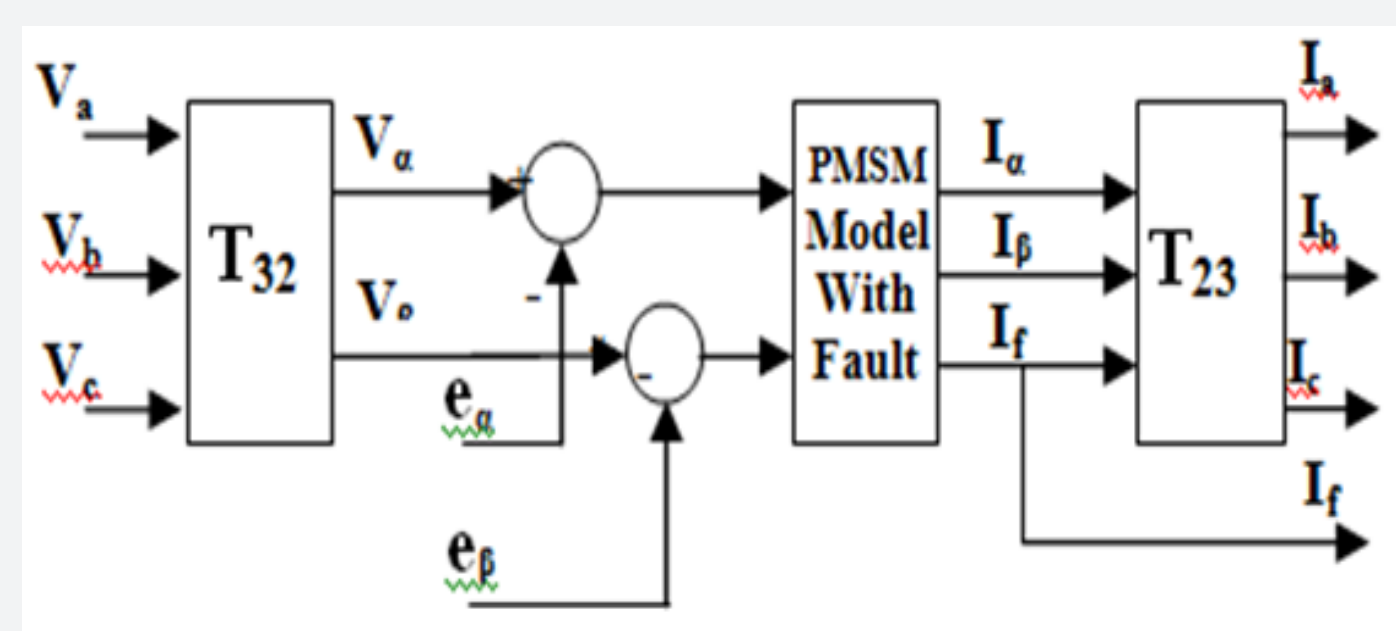

Figure 2: Block diagram of inter-turn fault model for PMSM.

\section{Simulation Results for PMSM with Inter-Turn Faults}

The proposed fault dynamic model (10) to (11) or (14) is used to modeling and study the PMSM with stator winding inter-turn fault. For this purpose, a four pair-pole PMSM. Using MATLABSimulink software, the fault model for PMSM is simulated under various inter-turn fault conditions.

Winding as in the external circuit is divided to two sub- winding $a_{s 1}$ and $a_{s 2}$ in series. With such a procedure, the current of the shorted part and flux linked with this branch is accessible.

First, it is considered that fault is occurred $2 \%$ of winding turns in the phase as and the other phases are healthy. The dynamic fault model is simulated for different values of fault insulation resistances $r_{f}=10 \Omega, 1 \Omega$ and $0.1 \Omega$. The simulation results, concerning the phase currents $\left(I_{a b c}\right)$ and the fault current $\left(i_{f}\right)$ and the torque electromagnetic are presented in Figure 3. 

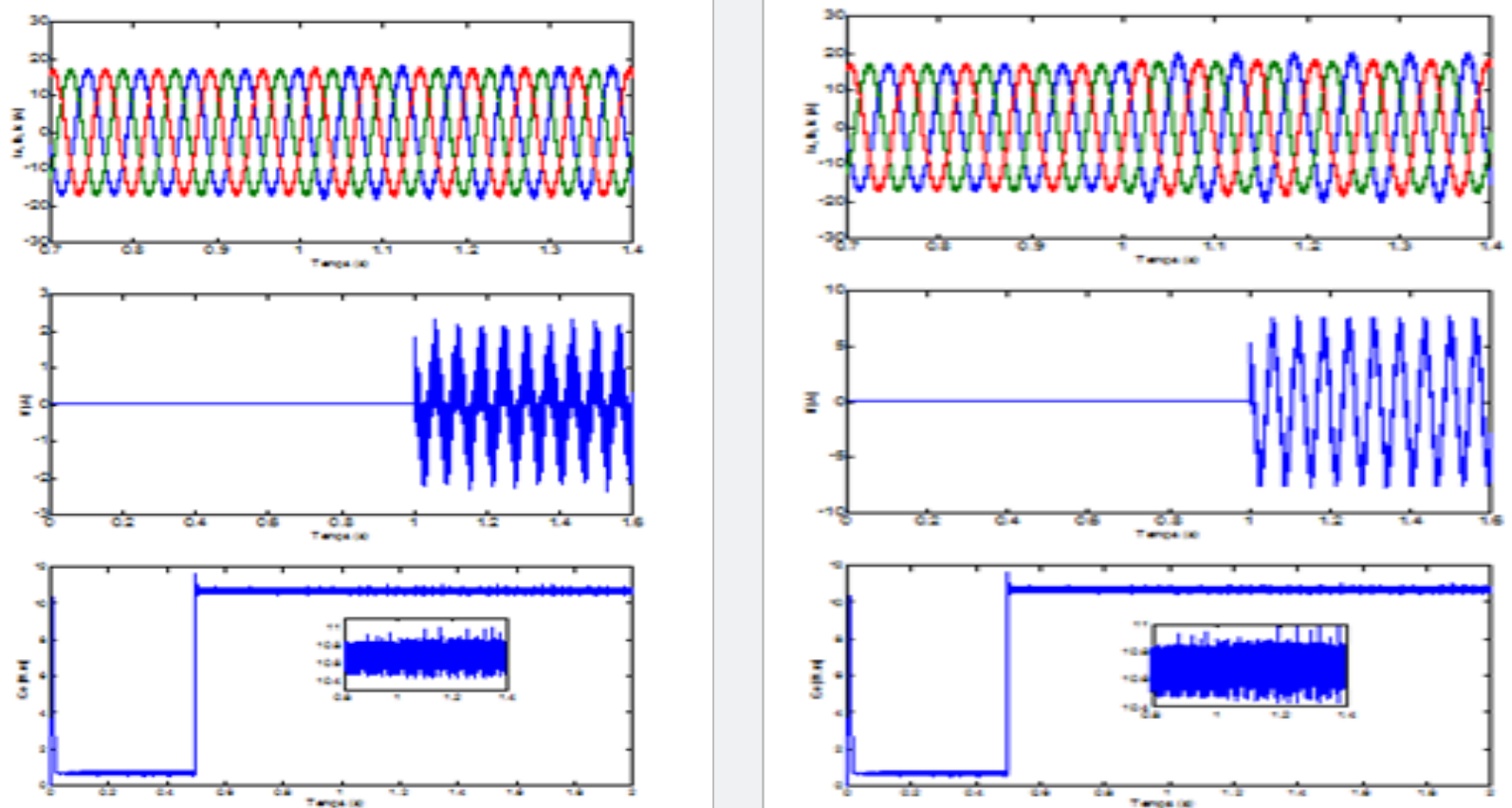

(a)

(b)
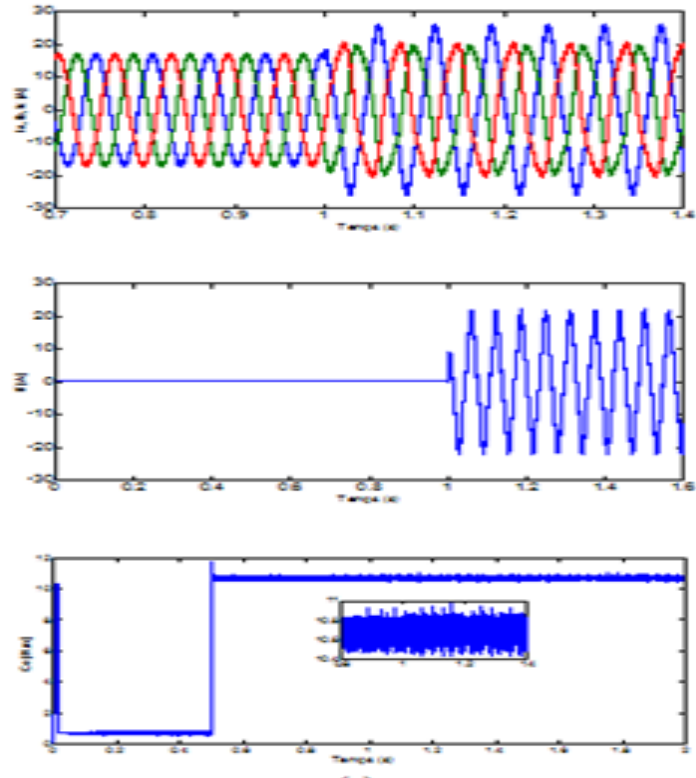

(c)

Figure 3: Phases currents, fault current and electromagnetic torque with severity of the fault (a): $\mu=2 \%$, (a) fault resistance $=10 \Omega$; (b) fault resistance $=1 \Omega ;$ and $(\mathrm{c})$ fault resistance $=0.1 \Omega$

It can be seen that when the resistance to faults decreases and follows to a complete short circuit, the amplitude of the fault current increase and the phase currents become more and more unbalanced, the phase which fault is occurred $\left(a_{s}\right)$, will be non-sinusoidal. Furthermore, the phases current will have not the same amplitude and will be unbalanced. The phase current witch the turn fault is occurred in $\left(a_{s}\right)$ is much higher than other phase currents $\left(b_{s}, c_{s}\right)$ where these phases are also affected by the fault. The torque electromagnetic present increase the fluctuation from the nominal value. This fault may also produce a small torque ripples.

Secondly, it is considered that fault insulation resistances $0.1 \Omega$. The dynamic fault model is simulated for different values of the severity of the fault (a): $\mu=1 \%$, (b): $\mu=2 \%$, (c): $\mu=3 \%$. The simulation results, concerning the phase currents ( $\left.I_{a b c}\right)$ and the fault current $\left(I_{f}\right)$ and the torque electromagnetic are presented in Figure 4. 

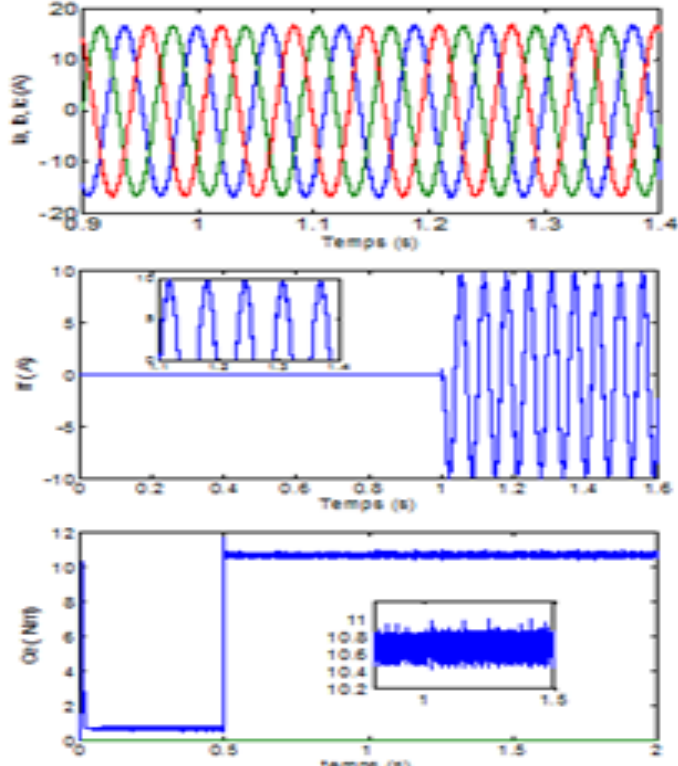

(a)
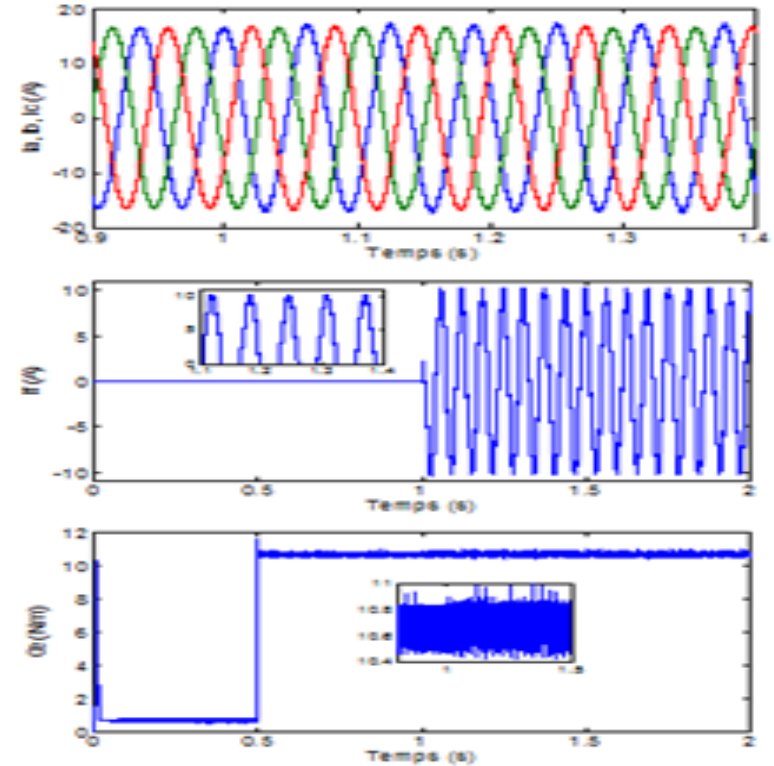

(b)
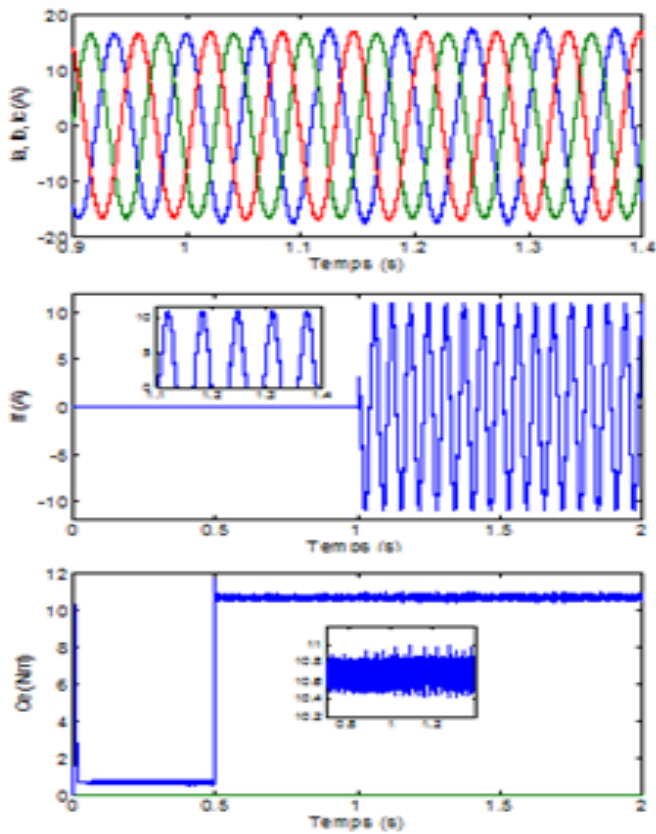

(c)

Figure 4: Phases currents and fault currents simulates and electromagnetic torque with fault resistance if $=0.1 \Omega$ and the severity of the fault (a): $\mu=1 \%$, (b): $\mu=2 \%$, (c): $\mu=3 \%$.

Before the fault the current if is zero. The phase currents are unbalanced with, in addition to increasing the amplitude of the current of the defective phase compared to the other phases when the number of turns in short-circuit increases, the system of phase currents is unbalanced, although these currents retain the periodic properties.

In stationary state (as it is the aim of this work), FFT analysis method is used to characterize signatures of different kind and strong of the short-circuit faults.

Measurements of stator currents in healthy mode and faulty mode obtained by applying with different values of the severity the fault $\mu$, and different values of fault insulation resistances $r_{f}$.

The Figure $5 \& 6$ shows the stator current FFT analysis in phase ' $a$ ' in healthy mode and faulty mode obtained by applying a $02 \%$ of the severity of the fault and insulation resistances $0.1 \Omega$. 


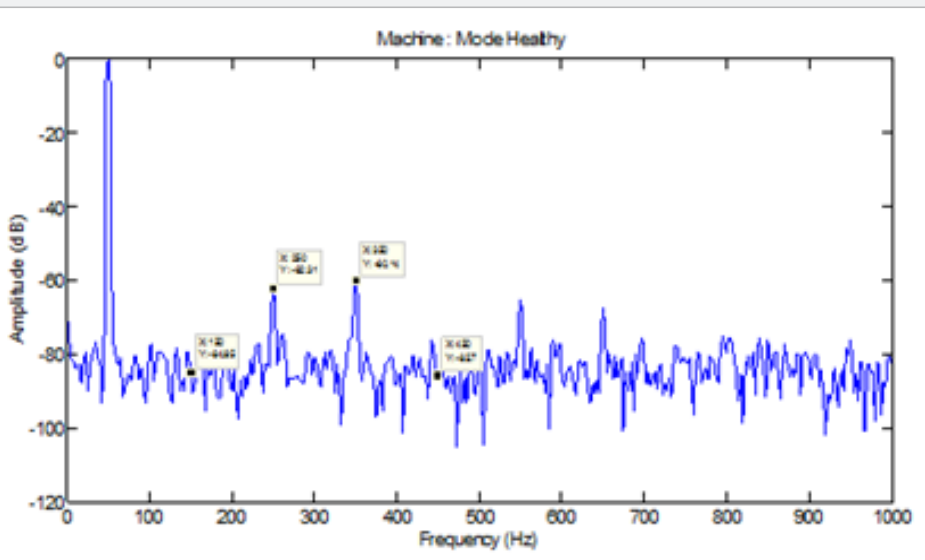

Figure 5: Spectral content of a healthy mode for PMSM, operating under rated load at $3000 \mathrm{r} / \mathrm{min}$.

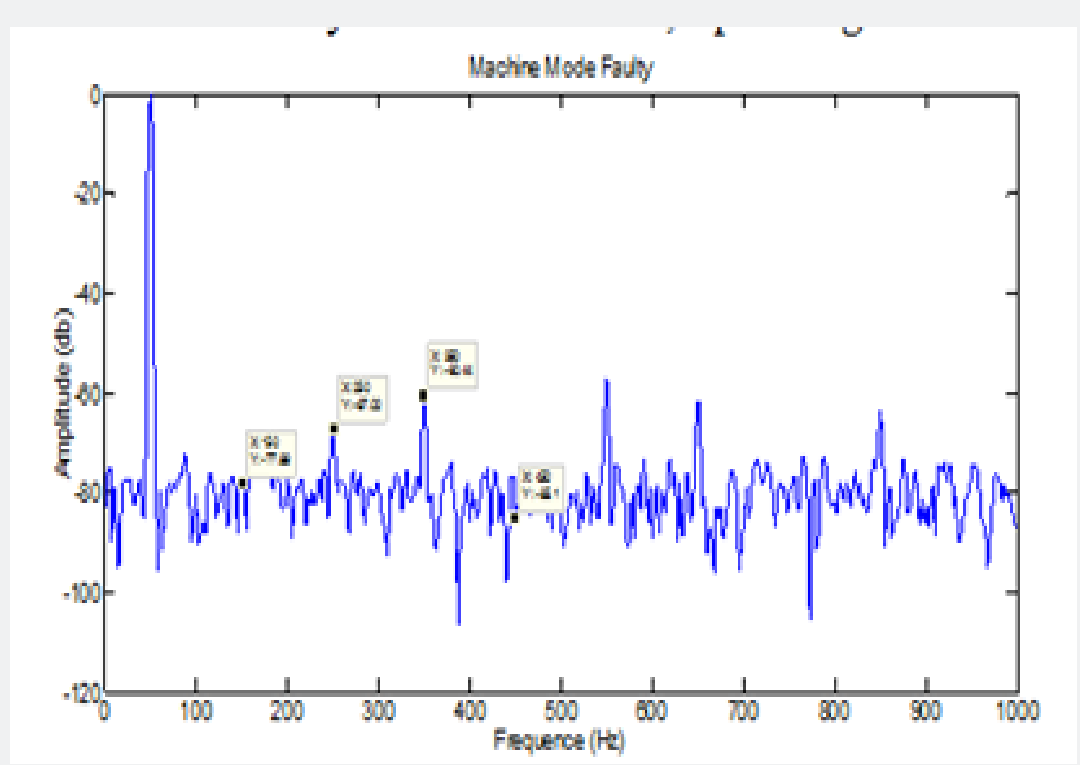

Figure 6: Spectral content of faulty mode for PMSM, operating under rated load at 3000 $/ \mathrm{min}$.

Table 1: FFT analysis of currents for different values of the severity.

\begin{tabular}{|c|c|c|c|c|c|}
\hline $\begin{array}{c}\text { State of PMSM } \\
\text { Amplitude (dB) }\end{array}$ & $\mathbf{5 0 ~ H Z}$ & $\mathbf{1 5 0 ~ H Z}$ & $\mathbf{2 5 0 ~ H Z}$ & $\mathbf{3 5 0 ~ H Z}$ & $\mathbf{4 5 0 ~ H Z ~}$ \\
\hline Heath mode & 0 & 0 & -85.25 & -61.63 & -60.14 \\
\hline $\begin{array}{c}1 \% \text { turns short } \\
\text { circuited }\end{array}$ & 0 & -55.61 & -71.88 & -59.74 & -72.53 \\
\hline $\begin{array}{c}2 \% \text { turns short } \\
\text { circuited }\end{array}$ & 0 & -48.58 & -68.17 & -59.44 & -70.14 \\
\hline $\begin{array}{c}\text { 3\% turns short } \\
\text { circuited }\end{array}$ & 0 & -44.72 & -70.5 & -62 & -71.53 \\
\hline
\end{tabular}

Table 1 shows the stator currents FFT analysis in the case of a single phase inter-turn fault in phase ' $a$ ' with different values of the severity of the fault (a): $\mu=1 \%$, (b): $\mu=2 \%$, (c): $\mu=3 \%$ turns short circuited and insulation resistances $0.1 \Omega$ at a speed of $3000 \mathrm{rpm}$. It is clear that third harmonic components are stronger than the healthy operating mode and there is an increase in this component with growth of the severity of the fault. 
Table 2: FFT analysis of currents for different values of fault insulation resistances.

\begin{tabular}{|c|c|c|c|c|c|}
\hline $\begin{array}{c}\text { State of PMSM } \\
\text { Amplitude }(\mathrm{dB})\end{array}$ & $50 \mathrm{HZ}$ & $150 \mathrm{HZ}$ & $250 \mathrm{HZ}$ & $350 \mathrm{HZ}$ & $450 \mathrm{HZ}$ \\
\hline Healthy mode & 0 & -85.25 & -61.63 & -60.14 & -85.7 \\
\hline $\begin{array}{c}\text { fault resistances } r_{f} \\
10 \S\end{array}$ & 0 & -55.61 & -71.88 & -61.37 & -56.76 \\
\hline $\begin{array}{c}\text { fault resistances } r_{f} \\
=1 \S\end{array}$ & 0 & -43.63 & -68.02 & -58.94 & -58.81 \\
\hline $\begin{array}{c}\text { fault resistances } r_{f}= \\
0.1 \S\end{array}$ & 0 & -32.91 & -67.51 & -57.34 & -57.69 \\
\hline
\end{tabular}

\section{Conclusion}

To identify the stator winding fault for PMSM, this paper proposed a model that can describe both normal and fault conditions. The model has been verified by comparing the simulation results with observations in related literature. However, because there is no quantified comparison, it is difficult to evaluate the accuracy of the developed model.

The fault detection problem can be approached by identifying the two parameters associated with fault location and fault severity. Because of the complex distribution of these two parameters in the fault model, it is very difficult to design a nonlinear identification algorithm. The FFT analysis algorithm is proposed to solve the detection/identification problem indirectly. Simulation studies on the developed model under both healthy and fault conditions demonstrate the performance of the proposed algorithm.

The proposed inter-turn fault model seems to be well adapted for PMSM health monitoring and inter-turn fault diagnosis.

\section{Appendix}

$$
\begin{gathered}
L_{s}=2.82 \mathrm{mH}, \phi_{f}=0.108 \mathrm{~Wb}, R_{s}=0.88 \Omega, p=4, \\
J=0.0006 \mathrm{~kg} . \mathrm{m} 2, f=0.007 \mathrm{~N} . \mathrm{m} . \mathrm{s} / \mathrm{rad}, \mathrm{In}=19 \mathrm{~A}, \\
L_{b o b}=0.00085 \mathrm{H}, M_{b o b}=-0.00005 \mathrm{H} .
\end{gathered}
$$

\section{References}

1. Lachtar S, Bahi T (2015) SVPWM performance of PMSM variable speed and impact of diagnosis sensors faults, International Conference on
Technologies and Materials for Renewable Energy, Environment and Sustainability 74: 679-689.

2. Jinpeng Y, Peng S, Wenjie D, Chen B, Chong L (2015) Neural networkbased adaptive dynamic area control for permanent magnet synchronous motors, IEEE Trans Neural Networks and is learning system 26(3): 640-645.

3. Ojo O, Osaloni O, Kshirsagar P (2002) Models for the control and simulation of synchronous type machine drives under various fault conditions in: 2002 Conference Record Ind. Appl. Conference, $37^{\text {th }}$ IAS Annual Meeting 3: 1533-1540.

4. Allbrecht PF, Appiarius JC, McCoy RM, owen EL, Sharma DK (1986) Assessment of the reliability of motors in utility applications - updated, IEEE Trans. Energy Convers 1(1): 39-46.

5. Haylock JA, Mecrow BC, Jack AG, Atkinson DJ (1999) Operation of fault tolerant machines with winding failures, IEEE Trans. Energy Convers 14(4): 1490-1495.

6. Harnefors L, Hinkkanen M (2014) Stabilization methods for sensorless induction motor drives-A survey, IEEE Journal of Emerging and Selected Topics in Power Electronics 2(2): 132-142.

7. Rusek J (2011) induction machine diagnostics based on FFT analysis of current space vector. AGH University of Science and Technology, Chair of Electrical Machines. Zeszyty Problemowe - Maszyny Elektryczne Nr 93/2011.

8. Anchehpoli SSM (2017) Analysis and diagnosis of faults in the PMSM drivetrains for series hybrid electrical vehicles (SHEVs), Electric power. Universite de Technologie de Belfort-Montbeliard, English.

9. Shi Y, Sun K, Huang L, Li Y (2012) Online identification of ermanent magnet flux based on extended kalman filter for IPMSM rive with position sensorless control, IEEE Trans. Industrial Electronics 59(11): 4169-4178.

10. Vaseghi B, Takorabet N (2011) Modelling and study of PM machines with inter-turn fault dynamic model-FEM model, Electric Power Systems Research 81(8): 1715-1722. 


Your next submission with Juniper Publishers
will reach you the below assets
- Quality Editorial service
- Swift Peer Review
- Reprints availability
- E-prints Service
- Manuscript Podcast for convenient understanding
- Global attainment for your research
- Manuscript accessibility in different formats
( Pdf, E-pub, Full Text, Audio)
- Unceasing customer service
Track the below URL for one-step submission
https://juniperpublishers.com/online-submission.php

